\title{
Direct and indirect immunofluorescence
}

\section{Imunofluorescência direta e indireta}

\author{
Valéria Aoki ${ }^{1}$ \\ Lígia M. I. Fukumori ${ }^{3}$ \\ Elder L. Freitas ${ }^{5}$
}

\author{
Joaquim X. Sousa $\mathrm{Jr}^{2}$ \\ Alexandre M. Périgo ${ }^{4}$ \\ Zilda N. P. Oliveira ${ }^{6}$
}

\begin{abstract}
Immunofluorescence is a valuable auxiliary diagnostic tool for autoimmune bullous diseases and inflammatory disorders, since their clinical and histopathologic findings may be inconclusive. It is a feasible laboratory method that requires experienced technicians and detects in situ and circulating immune deposits that may be involved in the pathogenesis of such skin diseases.

Keywords: Autoimmunity; Basement membrane; Fluorescent antibody technique; Pemphigus

Resumo: A imunofluorescência é um valioso instrumento auxiliar no diagnóstico das dermatoses bolhosas autoimunes e desordens inflamatórias, uma vez que seus achados clínicos e histopatológicos podem não ser determinantes. Consiste em um método laboratorial factível, que requer profissionais técnicos experientes, e detecta imunocomplexos in situ e/ou circulantes, que podem estar envolvidos na patogênese de tais enfermidades cutâneas.

Palavras-chave: Autoimunidade; Imunofluorescência; Membrana basal; Pênfigo
\end{abstract}

\section{INTRODUCTION}

Immunological reactions that involve the antigen-antibody binomial may be visualized or quantified using different labelers for the antigen or the antibody. Fluorochromes, enzymes, and radioactive and electro-opaque compounds are among the labelers most commonly used.

The beginnings of direct immunofluorescence date back to 1942, when Albert Coons et al. showed the labeling of antipneumococcal antibodies with fluorescein in the pulmonary tissue. ${ }^{1}$

Fluorochromes are dyes that absorb radiation (ultraviolet light), are excited by it and emit visible light. To function as labelers, they need to contain chemical groups capable of forming covalent bonds with protein molecules, emitting high fluorescence in the visible spectrum with a different coloration from that emitted by tissues. They must have a relatively simple conjugation, retention of the antibody activity in the labeled protein, and stability of the fluorescent conjugate obtained. One of the most used fluo- rochromes is fluorescein isothiocyanate (FITC), of green color, with absorption and emission peak wavelengths of 4901 and 5201 , respectively. Rhodamine, another agent used in DIF, of red color, has distinct absorption and emission peak wavelengths (520 and 610 1). Epiluminescence and confocal microscopy can be both used to read the results of DIF. ${ }^{2}$

Three distinct forms of fluorescence should be listed in the readings of IF assays: specific and nonspecific fluorescence and autofluorescence. Specific fluorescence is due to a reaction between the substrate and the protein labeled with fluorochrome (antigenantibody reaction). Nonspecific fluorescence occurs with coloration of tissues by free fluorescent dye or fluorescent proteins or both. Autofluorescence happens due to the natural fluorescence of tissues (yellow, blue) when exposed to ultraviolet light. ${ }^{3}$

Immunofluorescence was introduced into Dermatology in the 1960s, when Beutner and Jordon revealed through this technique tissue and circulating

Approved by the Editorial Board and accepted for publication on 31.07.2009

* Work conducted at the Department of Dermatology, Laboratory of Cutaneous Immunopathology, Faculty of Medicine, University of Sao Paulo (USP)- Sao Paulo (SP), Brazil.

Conflict of interest: None / Conflito de interesse: Nenbum

Financial funding / Suporte financeiro: CNPq-processo 303493/2008-9 e CNPq-processo 803070/87.0

Professor (Ph.D.), Department of Dermatology, Faculty of Medicine, University of Sao Paulo (USP)- Sao Paulo (SP), Brazil

Ph.D. student, Department of Dermatology, Faculty of Medicine, University of Sao Paulo (USP)- Sao Paulo (SP), Brazil.

Biologist, Laboratory of Cutaneous Immunopathology, Faculty of Medicine, University of Sao Paulo (USP)- Sao Paulo (SP), Brazil

Biologist, Laboratory of Cutaneous Immunopathology, Faculty of Medicine, University of Sao Paulo (USP)- Sao Paulo (SP), Brazil.

PIBIc, CNPq scholarship holder. Student at the Faculty of Medicine, University of Sao Paulo (USP)- Sao Paulo (SP), Brazil.

Professor (Ph.D.), Department of Dermatology, Faculty of Medicine, University of Sao Paulo (USP)- Sao Paulo (SP), Brazil.

(C2010 by Anais Brasileiros de Dermatologia 
antibodies in autoimmune vesico-bullous dermatosis, especially in pemphigus vulgaris (PV), pemphigus foliaceus (PF) ${ }^{4.5}$ and bullous pemphigoid (BP). ${ }^{6}$

Currently, immunofluorescence studies are vital for the laboratory diagnosis of autoimmune bullous dermatosis, but they are also important in the investigation of other diseases, such as inflammatory dermatosis (lupus erythematosus, lichen planus, porphyrias, vasculitis).

\section{A- DIRECT IMMUNOFLUORESCENCE}

The best site and evolution time of skin lesions to perform biopsy for direct immunofluorescence examination (DIF) depend on the disease under investigation. Generally, the biopsy should have an appropriate extension ( $4 \mathrm{~mm}$ punch) and depth that involves both the epidermis and dermis in sufficient proportion. In addition, the sample will be better for analysis when fewer traumas are involved in the procedure. $^{3}$

\section{The following sites are recommended for biopsy:}

In autoimmune vesico-bullous dermatosis, the best site is the perilesional region;

In collagenosis, the biospy should be done in the active lesion in evolution (avoid recent lesions, with less than 60 days);

In vasculitis, preference should be given to recent lesions with up to 24 hours of evolution.

After the procedure, the material can be immediately frozen in liquid nitrogen or placed in a proper transport medium - Michel's medium. ${ }^{7}$ Michel's medium is composed of ammonium sulphate, $\mathrm{N}$-ethyl-maleimide, and magnesium sulphate in a citrate buffer, which allows the conservation of the specimen for up to two weeks. ${ }^{8.9}$

The especimen is then sectioned in a cryostat into 4-micron fragments. Primary anti-human antibodies conjugated to FITC fluorescein (anti-IgA, anti-igG,

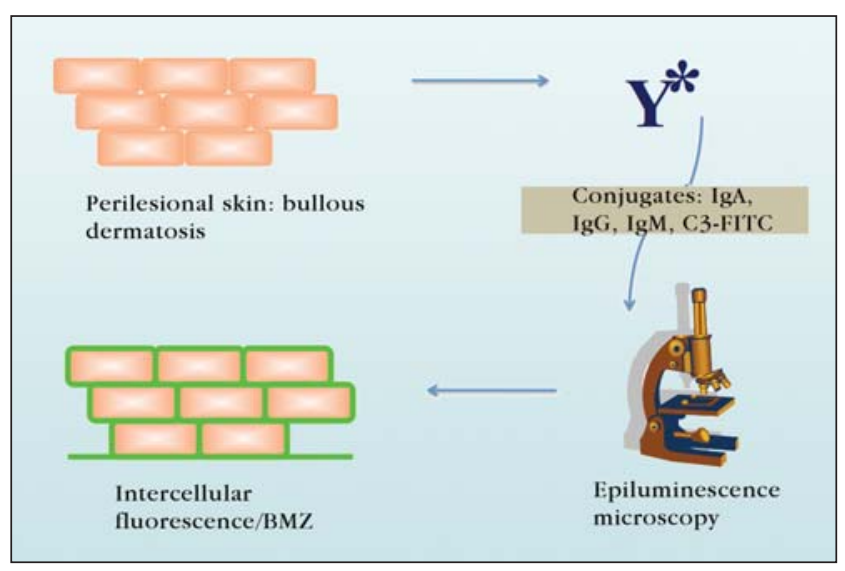

FIGURE 1: Direct immunofluorescence
anti-IgM, and anti-C3) are applied to each section and the reading is done on fluorescence microscopy (Figure 1$){ }^{3}$

\section{Epithelium}

There are two patterns of intraepithelial fluorescence: intercellular fluorescence, typical of pemphigus, and the fluorescence in the nuclei of keratinocytes (in vivo ANF), generally observed in connective tissue diseases.

\subsection{Intercellular fluorescence}

All forms of pemphigus are characterized by loss of cell adhesion, leading to acantholysis. This loss of adhesion results in intraepidermal blister formation. The level of cleavage allows us to differentiate the two main forms of pemphigus: pemphigus vulgaris and pemphigus foliaceus. In pemphigus vulgaris $(\mathrm{PV})$, the cleavage is suprabasal, whereas in pemphigus foliaceus (PF) it is intramalpighian. Direct immunofluorescence reveals intercellular fluorescence, of linear pattern, intraepidermal. ${ }^{10-11}$

\section{Pemphigus Foliaceus}

Findings from direct immunofluorescence on classical pemphigus foliaceus (PF) and endemic pemphigus foliaceus (EPF) show the same characteristics. IgG autoantibodies target desmoglein 1 (Dsg1), the main autoantigen in PF.

DIF: intercellular deposits of IgG and C3 are found throughout the epidermis (Figure 2a) in 100\% of the cases of active disease. ${ }^{3}$ Autoantibodies of the IgG class are also deposited in the oral squamous epithelium, despite the absence of clinical lesions of EPF in the mucous membranes. ${ }^{3,12}$ IgG subclasses may be employed, showing that in patients with active PF lesions the predominant IgG isotype is $\operatorname{IgG} 4$, in contrast to $\operatorname{IgG1}$, found more often in patients in remission. ${ }^{13}$

\section{Pemphigus Vulgaris}

IgG autoantibodies are deposited in the skin and oral squamous epithelium. In pemphigus vulgaris (PV) with lesions exclusive to the mucous membranes, IgG autoantibodies target desmoglein 3 (Dsg3), an autoantigen of higher expression in the lower portions of the epidermis. When mucocutaneous lesions are present, PV patients can also present antibodies against Dsg1 and indicate a worse prognosis of the disease. ${ }^{14}$ Similarly to PF, active PV lesions show IgG4, in contrast to ${ }_{15}$ patients who are in remission, where IgG1 prevails.

DIF: intercellular deposits of IgG and C3; the latter are predominantly located in the lower layers of 
the epithelia (Figure 2b) in PV with mucosa involvement in a $100 \%$ of the cases of active disease.

\section{Pemphigus Herpetiformis}

Pemphigus herpetiformis $(\mathrm{PH})$ is a variant of $\mathrm{PV}$ or $\mathrm{PF}$, where grouped pruriginous papules and vesicles are clinically observed. It resembles dermatitis herpetiformis. Findings from DIF are similar to those of PF or PV, that is, intraepithelial intercellular IgG deposits. ${ }^{8,16}$

\section{Paraneoplastic Pemphigus}

Paraneoplastic pemphigus (PNP) is a bullous dermatosis of severe prognosis, described by Anhalt et al. in 1990. The disease affects the skin and mucous membranes and is associated with neoplasms (Castleman's disease, lymphomas, thymomas). It is very similar to PV, but it shows diversity of autoantigens (reactivity with desmoglein 3 , desmoplakins, and BMZ antigens). ${ }^{17}$

DIF: Similar pattern to that of PV, but with occasional homogeneous deposits of IgG and C3 in the basement membrane zone (Figure 2c).

One way to differentiate PNP from PV is to perform indirect immunofluorescence (IIF) using as a substrate mouse vesicle epithelial cells (simple nonstratified epithelium, transitional). ${ }^{18}$ See IIF.

\section{IgA pemphigus}

IgA pemphigus (IgAP) is a rare neutrophilic acantholytic dermatosis. It is characterized by intercellular intraepidermal IgA deposits on DIF (Figure 2d). It can be classified into two types: subcorneal pustular dermatosis (SPD), whose autoantigen is desmocollin 1 (Dsc1) and intraepidermal neutrophilic dermatosis (IND). ${ }^{19-20}$

\section{2 IN VIVO ANTI-NUCLEAR FACTOR}

Immunoglobulin deposits, especially IgG or complement (C3) in the nuclei of keratinocytes (Figure 3), may appear in autoimmune disorders, such as lupus erythematosus, mixed connective tissue disease (MCTD), overlap syndrome, and vasculitis. This phenomenon is called in vivo antinuclear factor (ANF) and is of unknown immunopathology. Seventy-one percent of patients also show circulating antinuclear antibodies. This DIF pattern may be one of the first pieces of evidence of autoimmune disease, with positive predictive value for collagenosis varying from $75 \%$ to $88 \%$. ${ }^{21-22}$

\section{Basement membrane zone}

The basement membrane zone (BMZ) or dermo-epidermal junction presents several proteins or glucoproteins that serve as target antigens for vari- ous autoimmune bullous dermatoses. It is also a region prone to deposits of immunocomplexes in some inflammatory dermatoses, such as lupus erythematosus, vasculitis, lichen planus, and porphyrias. There are different fluorescence patterns of the BMZ. The most frequent are linear, homogeneous, granulous and reticulate.

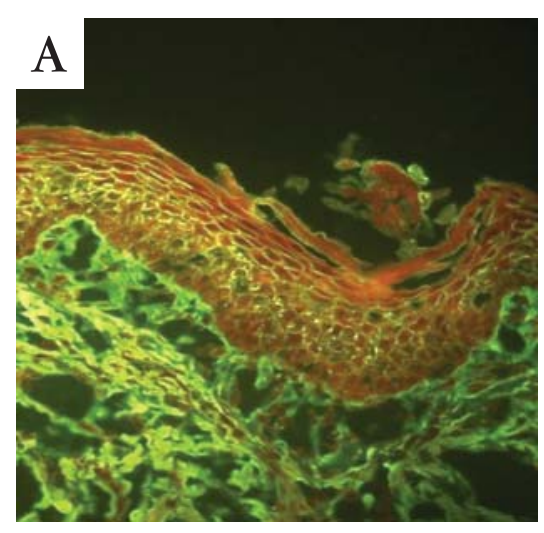

Figure 2: A. Pemphigus foliaceus. Linear, intercellular, intraepithelial IgG B. Pemphigus vulgaris. Linear, intercellular C3, lower layers of the epithelium; C. Paraneoplastic pemphigus. Linear, intercellular, intraepidermal and homogeneous, focal IgG in the BMZ; D. IgA pemphigus- intercellular, intraepithelial IgA
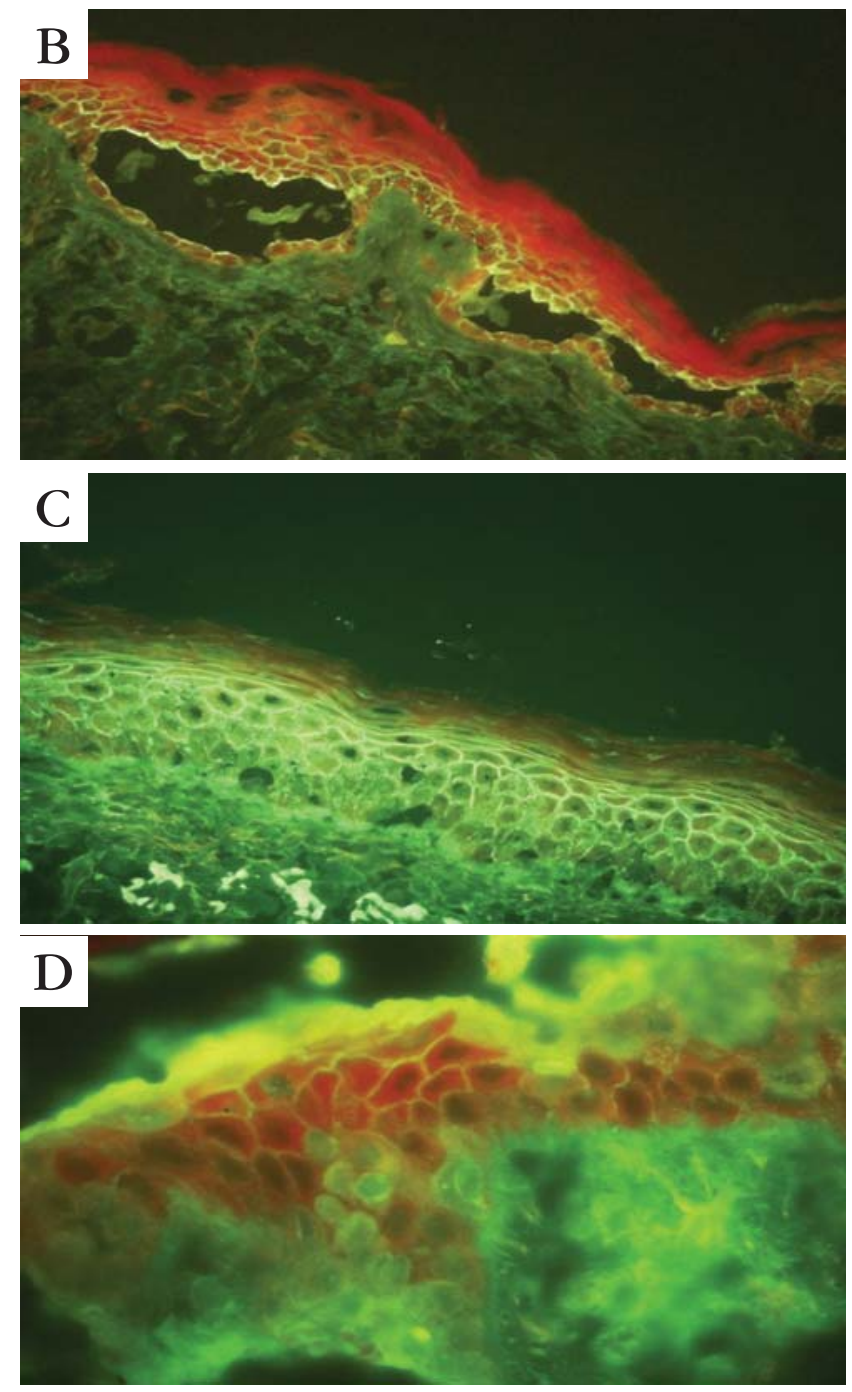


\subsection{LINEAR IGG AND/OR C3 DEPOSITS IN THE BASEMENT MEMBRANE ZONE \\ Bullous pemphigoid}

DIF: linear or fibrilar deposits throughout the basement membrane with anti-C3 conjugate (Figure $4 a)$ in $100 \%$ of the specimens; IgG deposits around $90 \%$. IgA and IgM are rarely observed. There is a higher expression of the BP antigen in flexural areas, being thus the preferable region for biospy. ${ }^{6,23}$

\section{Pemphigoid gestationis or herpes gestationis}

DIF: linear C3 deposits in the BMZ in 100\% of the cases. Linear IgG deposits in the BMZ are found in 30 to $40 \%$ of the cases. ${ }^{24-25}$

\section{Mucous Membrane Pemphigoid (MMP)}

DIF: Linear IgG and C3 deposits in the BMZ, indistinguishable from bullous pemphigoid. IgA in the BMZ occurs in about $20 \%$ of the cases. Positivity of the oral mucosa is around 90 to $100 \%$, whereas in the conjunctiva it varies from 65 to $85 \%$. $^{26-27}$

\subsection{MULTIPLE LINEAR DEPOSITS (IGA, IGG, IGM AND/OR C3) IN THE BASEMENT MEMBRANE ZONE}

They facilitate the diagnosis of anti-collagen VII dermatoses: epidermolysis bullosa acquisita (EBA) and bullous systemic lupus erythematosus (BSLE).

Epidermolysis bullosa acquisita and bullous systemic lupus erythematosus

DIF: Linear or homogeneous IgG, IgM, IgA, and $\mathrm{C} 3$ deposits in the basement membrane zone (Figure 4b). In EBA, IgG deposits are more intense and are present in nearly $100 \%$ of the cases, as compared with C3. IgA appears in $67 \%$ and IgM in $50 \%$ of the specimens. ${ }^{3,28}$ In BSLE, $60 \%$ of patients show DIF results similar to those of EBA. In the remaining cases, deposits may be granulous and IgA appears to be the most frequent immunoglobulin. ${ }^{28}$

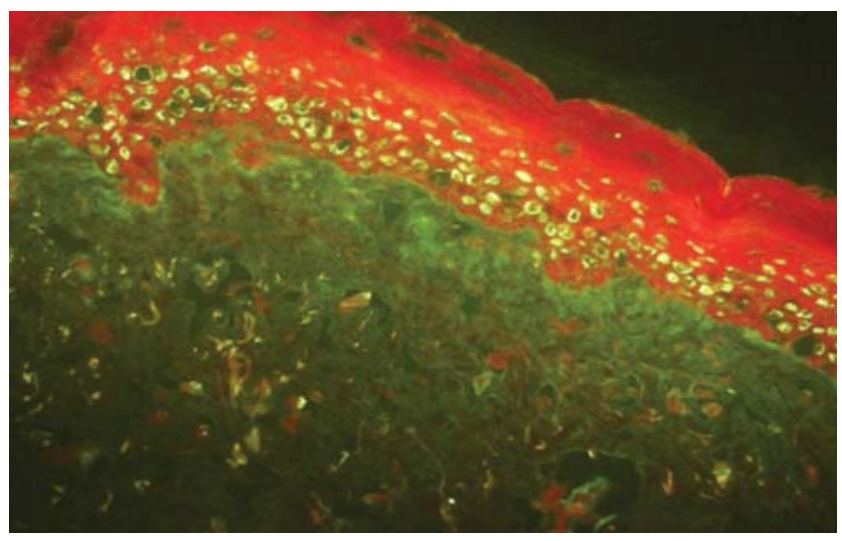

FIGURE 3: in vivo ANF

\subsection{LINEAR IGA DEPOSITS IN THE BASEMENT MEMBRANE ZONE}

Linear IgA bullous dermatosis (LAD)

Linear IgA dermatosis is distinct from dermatitis herpetiformis. DIF is essential in the differential diagnosis of these two diseases, especially because there is no intolerance to gluten in LAD. The autoantigen is a $120 \mathrm{kDa}$ glucoprotein and represents a portion of the $180 \mathrm{kDa}$ (BP180) autoantigen of bullous pemphigoid, which underwent sheddase. ${ }^{30-31}$

DIF: Linear or homogeneous IgA deposits in the basement membrane zone in $80-100 \%$ of the patients (Figure 4c). Occasional C3 and IgG deposits may be found in the BMZ. ${ }^{3,28}$

\section{DERMAL FLUORESCENCE}

In this group we highlight granulous deposits at the top of the dermal papillae in dermatitis herpetiformis (DH) and the fluorescence observed in the vessel walls in vasculitis and porphyrias. For didactic reasons, we have included in this group findings about lichen planus, which most often correspond to cytoid bodies below the BMZ and with no established clinical significance.

\section{Dermatitis herpetiformis}

DIF is an important diagnostic tool in $\mathrm{DH}$, since deposits of immunocomplexes (IgA) in the dermal papillae diagnose the gluten-sensitive disease.

DIF: granulous, fibrillar or dotted IGA deposits are found in the dermal papillae (Figure 5a). The IgA subtype consists basically of IgA1; IgA2 rarely occurs. Other immunoglobulins and C3 may be found in the dermal papillae, but are rare. ${ }^{32.33}$

\section{VASCULITIS}

In vasculitis, immunodeposits are often located in the walls of postcapillary venules of the superficial dermis, since the most frequent processes are leukocytoclastic vascullitis (LCV) and Hennoch-Schönlein purpura (HSP). The specimen should be collected within the first 24 hours because immunocomplexes are rapidly degrated.

DIF: In Hennoch-Schönlein purpura, IgA deposits of granulous pattern predominate $(75-100 \%)$ in the vessel walls of the superficial dermis (Figure 5b). In leukocytoclastic vasculitis, deposits on the vascular walls are predominantly constituted by C3, followed by IgM and IgG, and they are fibrillar. In cryoglobulinemias, C3 predominates and sometimes IgM and IgA are observed in the vessels. In collagenosis, the most frequently observed deposits are of IgG, IgM, and $\mathrm{C} 3 .{ }^{28,34}$ 

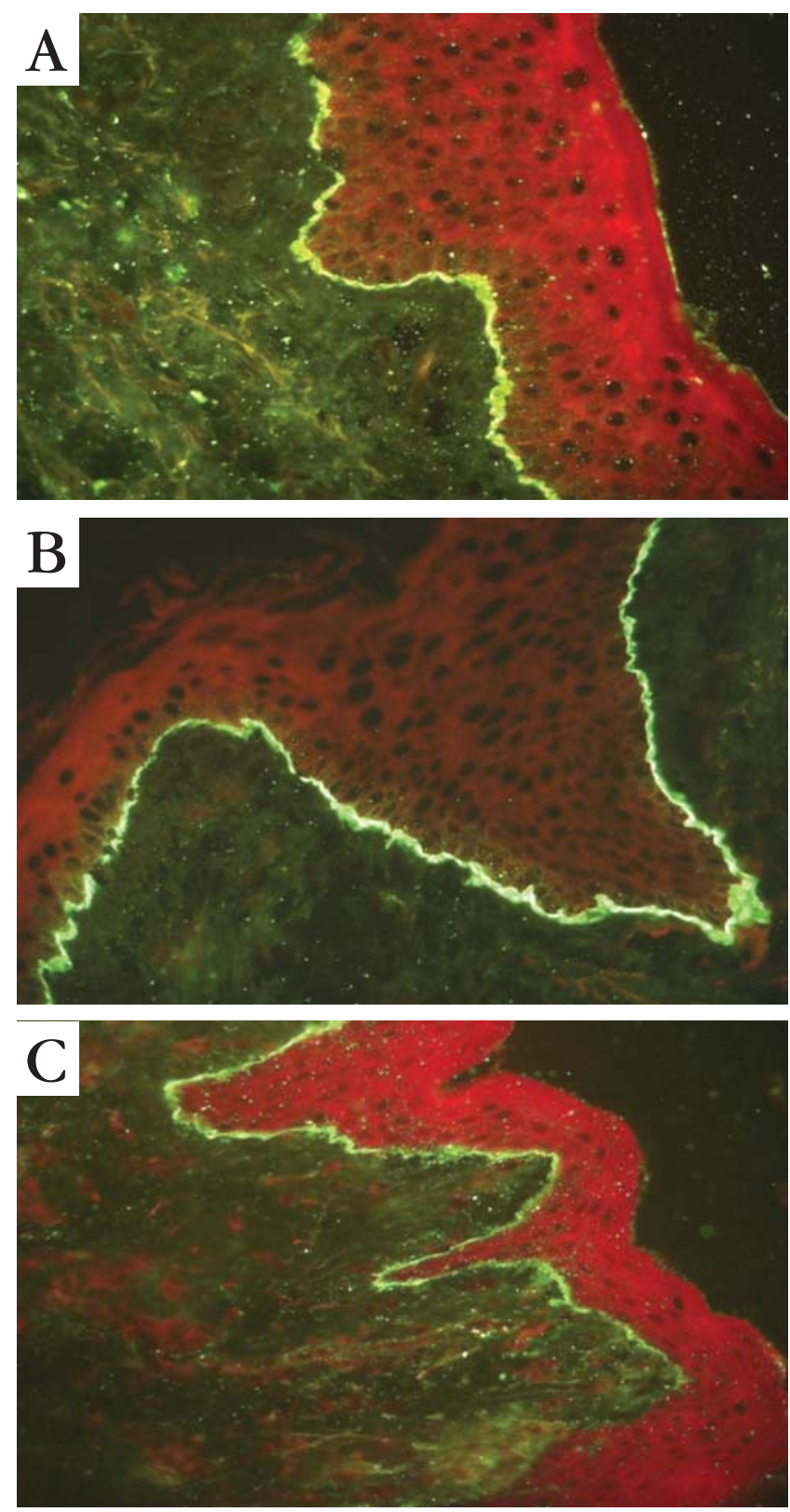

Figure 4: A. Bullous pemphigoids - Linear C3 in the BMZ; B. EBA - Linear IgG in the BMZ; C. Linear IgA bullous dermatosis -IgA deposits in the BMZ

\section{Porphyrias}

Lesioned skin in porphyria (cutanea tarda, erythropoietic, variegate, coproporphyria) shows homogeneous deposits of IgG, IgM (rare), C3, and IgA in the walls of dilated vessels in the papillary dermis and throughout the BMZ. The frequency of such deposits in active lesions may reach $100 \%$, whereas in the normal skin of patients positivity is of $50 \%$ (Figure $5 \mathrm{c}$ ). ${ }^{3,28}$

\section{Lichen planus}

DIF: presence of fluorescent cytoid bodies with IgM (Figure 5d), and less frequently IgA and IgG.
Granulous IgM deposits may be found in the BMZ. However, findings do not indicate the diagnosis of lichen planus because they can be associated with other conditions (LE, BP). ${ }^{35-36}$

\section{Direct immunofluorescence of lupus erythematosus}

In lupus erythematosus (LE), immunocomplexes target the nuclear components of keratinocytes and structures of the basement membrane zone. DIF aids in the diagnostic confirmation of lupus erythematosus, distinguishing it from other diseases. IgG, IgM, IgA, and C3 deposits may occur, in addition to other immunoreactants in the BMZ. There are several deposit patterns in the BMZ, such as: homogeneous, fibrillar, linear, and granulous, which can be focal or continuous. Fluorescent cytoid bodies can be observed in the dermis in the dermo-epidermal junction with IgM or IgA. Prevalence of immunoglobulins in the BMZ is partly determined by age, localization and morphology of the lesion, activity of the disease, and treatment. ${ }^{3,28,37}$

\section{Chronic cutaneous lupus erythematosus}

In chronic cutaneous lupus erythematosus (CCLE), the occurrence of immunoreactant deposits varies between 60 and $90 \%$. DIF often shows positivity in CCLE after the second month of the disease. The site of the biopsy is extremely important: lesions in the trunk are generally negative, while those in the cephalic portion, neck, and upper extremity show more than $80 \%$ of positivity. IgG and IgM with homogeneous, granulous or reticulate pattern (Figure 6) are the most frequent, and most authors find greater positivity for IgM. DIF is usually negative in healthy skin. 3,28,37

Fluorescent cytoid bodies (IgA and IgM) are found in the papillary dermis and represent degeneration of basal keratinocytes. They are not exclusive to LE, since they are frequently found in lichen planus (LP) and other inflammatory dermatoses.

\section{Subacute cutaneous lupus erythematosus (SCLE)}

DIF findings are similar to those of CCLE, with positivity around 54 and $100 \%$ of the cases. Nevertheless, fluorescence of the BMZ is often granulous and occasional fluorescence of the nuclei of keratinocytes occurs - the in vivo ANF phenomenon. ${ }^{3,22,28}$

\section{Systemic lupus erythematosus}

In systemic lupus erythematosus (SLE) immunoreactant deposits (lupus band test $=$ LBT) ${ }^{37}$ are essential in the diagnosis and prognosis of the disease when associated with clinical findings and serologic tests. As a diagnostic test, LBT is 60 to $90 \%$ sensitive in the photoexposed normal skin of SLE patients, as compared with non-exposed areas (40- 

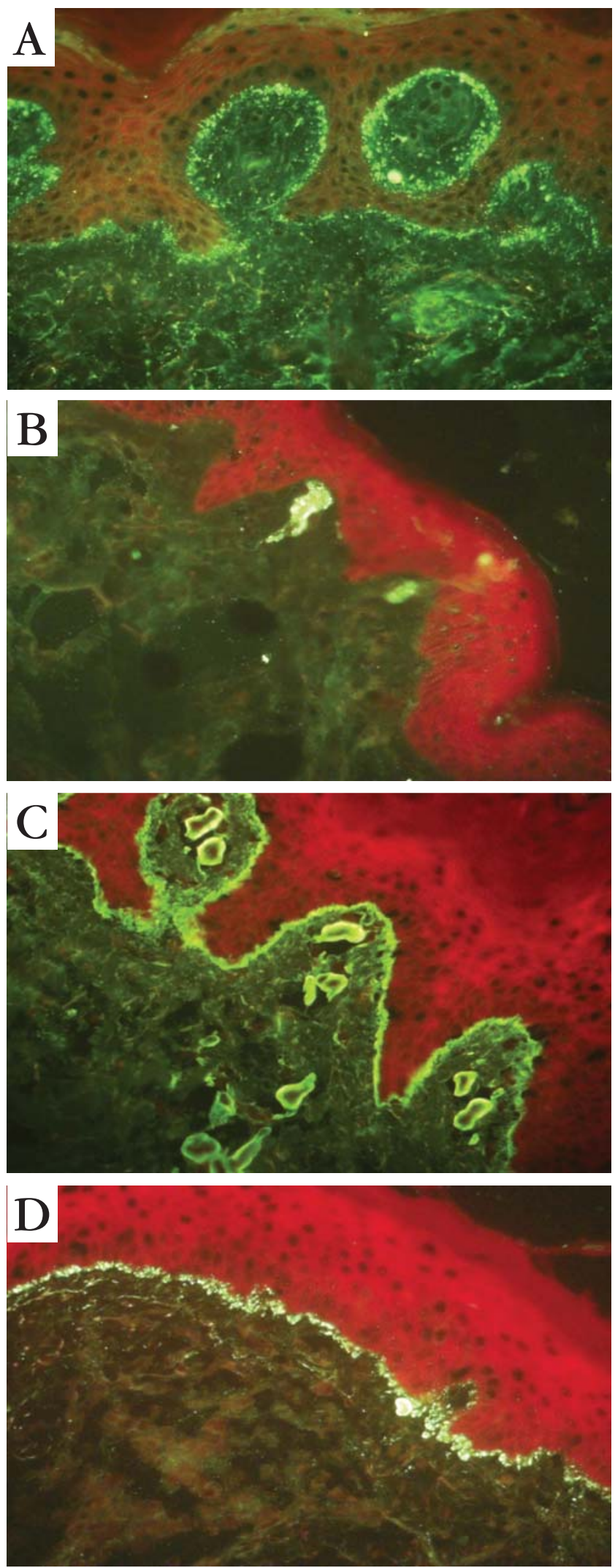

FigurA 5: A. Dermatitis herpetiformis - Granulous IgA, top of the dermal papillae; B. Hennoch-Schonlein purpura. IgA in the papillary dermal vessel walls; C. Porphyria cutanea tarda. Homogeneous IgG in the BMZ and in the dermal vessel walls; $\mathbf{D}$. Lichen planus. IgM in the BMZ and fluorescent cytoid bodies in the papillary dermis

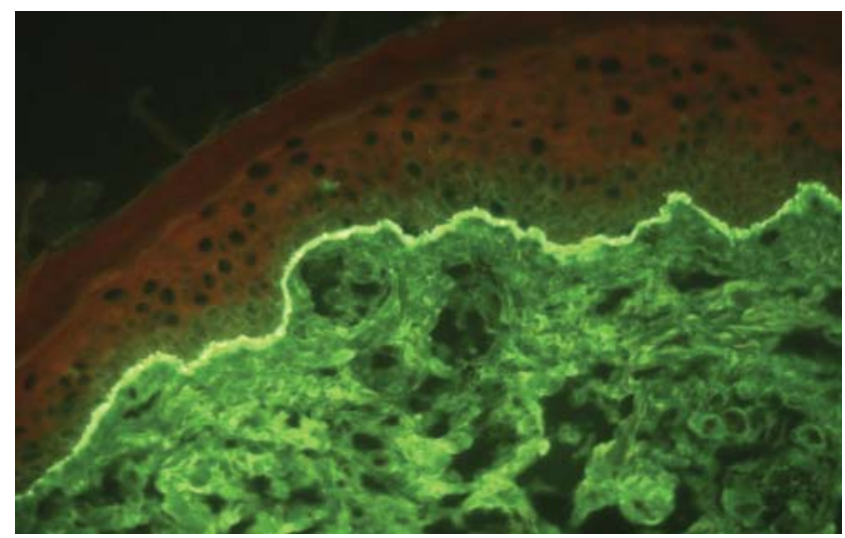

Figure 6: Lúpus eritematoso - IgG homogênea na ZMB

$60 \%)$. The area currently recommended is the deltoid area or dorsal portion of the forearm. As a prognostic test, LBT should be performed in the non-exposed area of normal skin (gluteal region and flexor portion of the forearm).

In a study by Gilliam et al. ${ }^{38}$ with 42 SLE patients, 55\% showed immunoglobulin deposits in the uninvolved skin (LBT). LBT was positive in $70 \%$ of the patients with renal LE and in 31\% of the LE cases without renal aggression.

Immunocomplex deposits involve various immunoglobulins, associated or not with $\mathrm{C} 3$. The most frequent association is of $\mathrm{IgG} / \mathrm{IgM}$. Fluorescence can also occur in the dermal vessel walls, annexes and in the nuclei of keratinocytes. ${ }^{3,28}$

\section{B- INDIRECT IMMUNOFLUORESCENCE}

Indirect immunofluorescence (IIF) is an important diagnostic tool in autoimmune vesico-bullous dermatosis (VBD) and allows the evaluation of circulating autoantibodies. Often, the clinical and laboratorial correlation of patients is possible.

The IIF technique employed in studies of circulating antibodies in VBD uses the healthy epithelium as substrate. Substrates vary based on the protocols of each laboratory, but Brazilian researchers consider healthy human skin obtained from prepuce, breasts or eyelids ideal (easy obtention, good antigenicity), as a substitute for monkey esophagus (Figure 7).

An example of an IIF protocol is described below: the skin is cryosectioned $(4 \mu)$ and the fragments are placed in silanized slides. The patient's diluted serum is incubated (to a ratio of 1:20) with the substrate for 30 minutes at room temperature in a humid chamber, followed by trizma base buffer/calcium (TBS $\left.\mathrm{Ca}^{2+}\right)$ rinse. The reaction is developed by secondary antihuman antibodies (igG, IgA, IgM, and C3) produced in rabbits, murines or caprines, and conjugated with fluorescein isotiocianate (FITC). The reading of the reaction is done on epiluminescence microscopy. 
In quantitative tests, the resulting titer is the one that still detects fluorescence in the substrate. ${ }^{3,5}$

\section{Intraepidermal bullous dermatosis: pemphigus} Similarly to DIF, IIF on pemphigus shows intercellular fluorescence, of linear pattern, intraepithelial (Figure 8).

\section{Pemphigus foliaceus}

IIF: classical PF and endemic PF (EPF) show the same intercellular pattern of fluorescence- linear, intercellular, intraepithelial. The autoantibodies of the IgG class target desmoglein 1 (Dsgl- $160 \mathrm{kDa}$ glucoprotein), its main autoantigen. ${ }^{5,38}$ IIF is $90-100 \%$ sensitive. ${ }^{3,5}$ In invasive bullous or erythrodermic PF, IIF titers may be high ( $>1: 5120)$.

The dominant IgG subclass in EPF is $\mathrm{IgG}_{4}$. Autoantibodies of the IgG1 and IgG2 subclasses are detected in low titers in patients in remission and in healthy individuals living in endemic areas, whereas IgG3 is absent. ${ }^{5,13,39}$ IgG4 is a pathogenic isotype capable of inducing EPF in an experimental model. Studies have shown that low IgG4 titers in IIF can be found in 56\% of EPF patients in clinical remission, which could represent a greater possibility of reactivation of the disease if these autoantibodies target the extracellular pathogenic epitopes of Dsg1 (EC 1-2). ${ }^{40}$

\section{Pemphigus vulgaris}

In PV, the autoantibodies of the IgG class target desmoglein 3 (Dsg3), an autoantigen of higher expression in the squamous epithelia. When mucocutaneous lesions are present, patients may also present antibodies against Dsg1. ${ }^{14,41}$

IIF: fluorescence pattern similar to that of PF. Patients show 75 to $100 \%$ of positivity for antiepithelial antibodies of the IgG class. Predominance of IgG4 also occurs in the active disease. ${ }^{5,14-15,41}$

\section{Paraneoplastic pemphigus}

In PNP there is recognition of autoantigens of

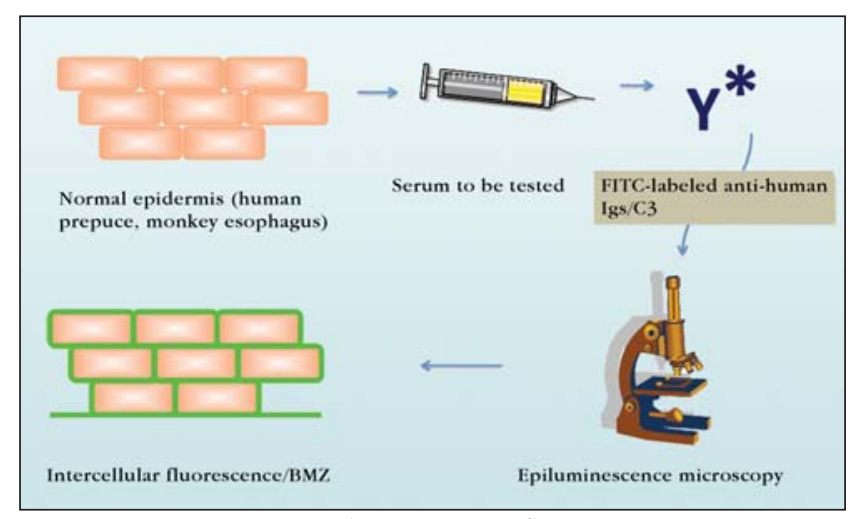

FIGURE 7: Indirect immunofluorescence

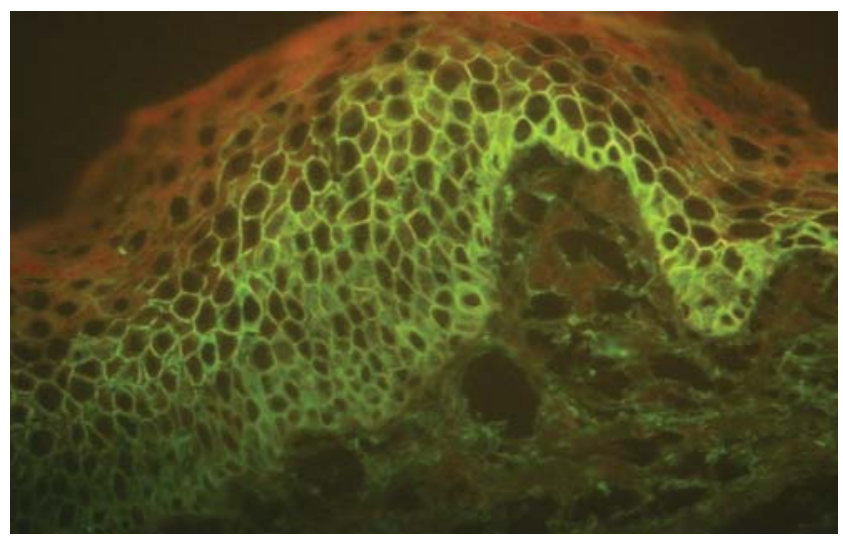

FIGURE 8: Pemphigus. IIF- intercellular, intraepithelial IgG

mouse vesicle epithelium in $83 \%$ of the cases (Figure 9 ). In suspicious cases with negative IIF (mouse vesicle epithelium), other immunological tests are necessary, such as immunoprecipitation to dismiss the diagnosis of PNP. In PF and PV, IIF that uses mouse vesicle epithelium as a substrate is often negative, but there are patients, especially those with PV with predominance of mucosal lesions, who show reactivity against desmoplakin $1 .{ }^{17-18,42}$

\section{IgA pemphigus}

IIF: It is characterized by intraepidermal intercellular IgA deposits and it is positive in about $50 \%$ of the cases. ${ }^{19-20}$

\section{Subepidermal bullous dermatosis Bullous pemphigoid}

IIF: It shows circulating antibodies of the anticollagen XVII (BP180) IgG class in 70\% of the patients. It appears that there is no correlation between antibody titers and the extension or activity of the disease. ${ }^{3,28,43}$

\section{Epidermolisis bullosa acquisita/ Bullous systemic lupus erithematosus}

IIF: It shows circulating anti-BMZ IgG antibodies in $25-50 \%$ of the patients. There is no correlation between antibody titers and the extension or activity of the disease. The fluorescence pattern of EBA is similar to that of BP. The salt-split skin technique allows their differentiation through the localization of fluorescence.

\section{IIF: Salt-Split Skin}

The salt split skin technique (SS) was developed in $1984^{44}$ and increased the sensitivity of detection of anti-BMZ antibodies in subepidermal VBD when compared with the non-cleaved substrate (skin).

The SS technique consists in incubating normal human skin in a sodium chloride solution ( $\mathrm{NaCl} 1.0$ M) for 72 hours at $4^{\circ} \mathrm{C}$, with a daily change of solution 


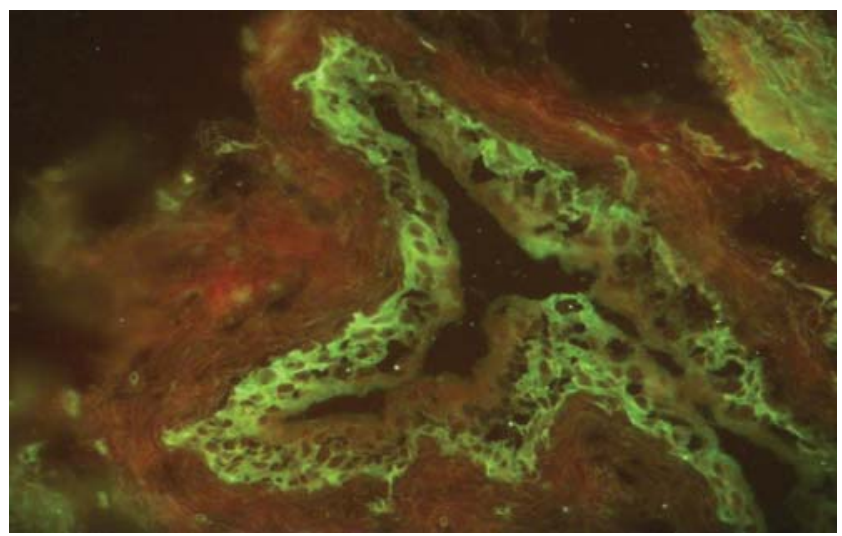

FigURE 9: Paraneoplastic pemphigus. IIF (mouse vesicle epithelial cells)- intercellular IgG

during this period. In this way, the split or artificial separation of skin is induced in the lamina lucida of the BMZ. Splitting separates the autoantigens of BP and EBA. The epidermal side contains antigens associated with the hemidesmosome (plectin, BP antigen BP 230) and the dermal side consists of laminin 5 (below the lamina lucida) and types IV (lamina densa) and VII (anchorage fibrillas) collagens.

About $85 \%$ of the serum of patients with BP show binding of antibodies of the IgG class to target antigens at the top of the blister (epidermal side) or on both sides of the cleavage in 15\% of the cases (Figure 10a). This is due to the localization of BP antigens, which are present in the hemidesmosome $\left(\mathrm{PBGA}_{1}\right)$ or in the lamina lucida $\left(\mathrm{BPGA}_{2}-\mathrm{BP} 180\right.$ or type XVIIa collagen). ${ }^{44}$

In EBA or SBLE patients there is reactivity on the bottom of the blister (dermal side) because type VII collagen is found in anchorage fibrillas in the sublamina densa region (Figure 10b). EBA shows about $50 \%$ of positivity in the SSS.

\section{Mucous membrane pemphigoid}

The main autoantigen of mucous membrane pemphigoid (MMP) is laminin 5 (calinin), but PB180 and $\mathrm{a} 6 \mathrm{~b} 4$ are also cited.

IIF: it is rarely positive, around $10 \%$ of patients with anti-IgG against the BMZ. The best substrate is the healthy human mucosa (oral or vaginal). ${ }^{3,28}$

SS: positivity in the epidermal and dermal side of the cleavage. ${ }^{27,28}$

\section{Pemphigoid gestationis (PG) or herpes gestationis (HG)}

HG is considered a specific form of $\mathrm{BP}$ that occurs during pregnancy.

IIF: circulating antibodies of the $\mathrm{IgG}_{1}$ subclass in $10-20 \%$ of the cases. These patients' serum contains complement-fixing anti-BMZ antibodies, known as
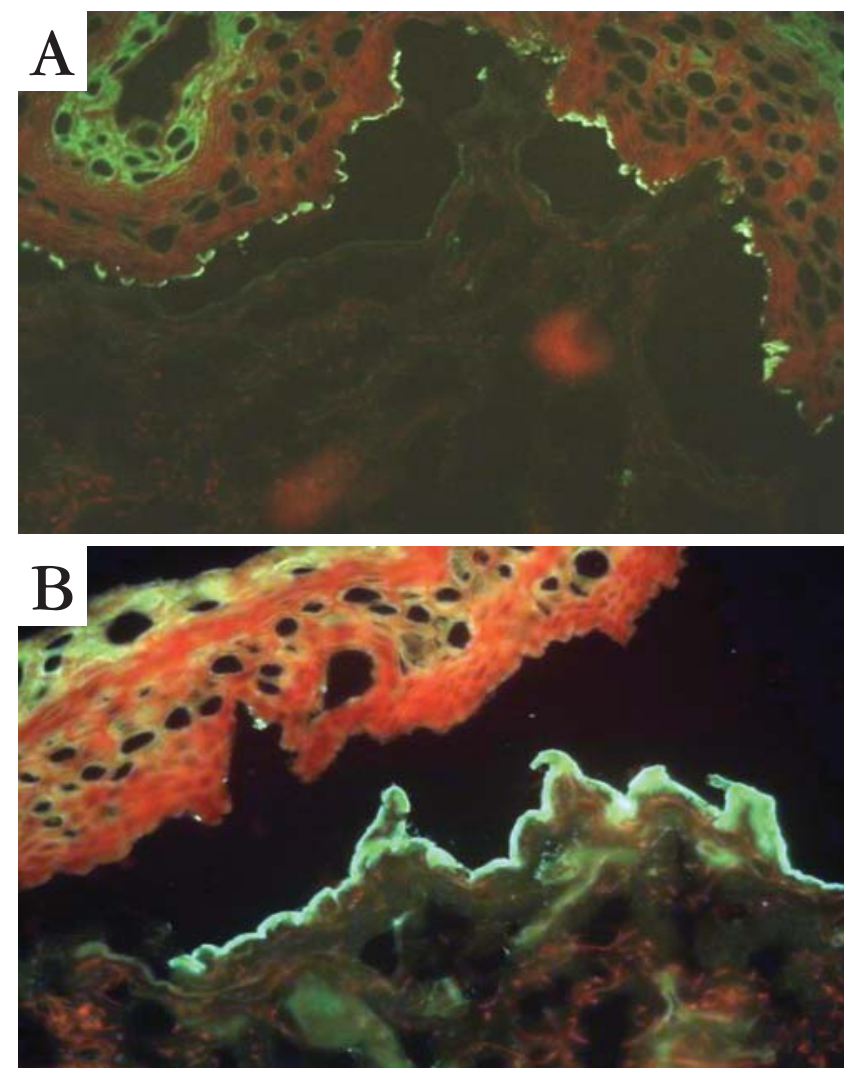

Figura 10: A. Bullous pemphigoid. Salt Split Skin, epidermal side (IgG); B. Epidermolisis bullosa acquisita. Salt Split Skin, dermal side (IgG)

HG factor. In SS, they usually show fluorescence in the epidermal side of the cleavage. ${ }^{28}$

HG factor: It is an amplified IIF technique, to which a complement source is added (fresh normal human serum). It is used when there is doubt about diagnosis and increases IIF sensitivity in HG to $50 \% .{ }^{28}$

\section{Linear IgA bullous dermatosis (LAD)}

IIF: circulating IgA antibodies are rare ( 7 to $30 \%$ of the cases) and IIF should be performed to dismiss other dermatoses such as BP. ${ }^{3,28,30}$

SS: positive on the epidermal side in $60-70 \%$ of the cases. ${ }^{3,30}$

\section{Dermatitis herpetiformis}

IFF: it is often negative for circulating IgA antibodies.

In conclusion, we can consider immunofluorescence (direct and indirect) to be a sensitive and specific method to detect in situ and circulating autoantibodies in autoimune vesicle-bullous dermatosis; in inflammatory dermatosis, it can be an auxiliary laboratory tool in the conclusive diagnosis of the disease under investigation. 


\section{REFERENCES}

1. Coons AH, Creech HJ, Jones RN, Berliner E. The Demonstration of Pneumococcal Antigen in Tissues by the Use of Fluorescent Antibody. J Immunol. 1942; $45: 159-70$.

2. Beutner EH. The development of immunofluorescence and the immunopathology of the skin. Int J Dermatol. 2003;42:99-109.

3. Aoki V. Imunofluorescência, immunoblotting e imunoprecipitação. In: Sampaio SA, Rivitti E, eds. Dermatologia. 3 ed. Sao Paulo: Artes Médicas; 2007. p.127-38.

4. Beutner EH, Jordon RE. Demonstration of Skin Antibodies in Sera of Pemphigus Vulgaris Patients by Indirect Immunofluorescent Staining. Proc Soc Exp Biol Med. 1964;117:505-10.

5. Aoki V, Huang MH, Perigo AM, Fukumori LM, Maruta CW, Santi CG, et al. Endemic pemphigus foliaceus (fogo selvagem) and pemphigus vulgaris: immunoglobulin $\mathrm{G}$ heterogeneity detected by indirect immunofluorescence. Rev Hosp Clin Fac Med Sao Paulo. 2004;59:251-6.

6. Jordon RE, Beutner EH, Witebsky E, Blumental G, Hale WL, Lever WF. Basement zone antibodies in bullous pemphigoid. JAMA. 1967;29;200:751-6.

7. Mutasim DF, Pelc NJ, Supapannachart N. Established methods in the investigation of bullous diseases. Dermatol Clin. 1993;11:399-418.

8. Santi CG, Maruta CW, Aoki V, Sotto MN, Rivitti EA, Diaz LA. Pemphigus herpetiformis is a rare clinical expression of nonendemic pemphigus foliaceus, fogo selvagem, and pemphigus vulgaris. Cooperative Group on Fogo Selvagem Research. J Am Acad Dermatol. 1996;34:40-6.

9. Morrison LH. When to request immunofluorescence: practical hints. Semin Cutan Med Surg. 1999;18:36-42.

10. Mihai S, Sitaru C. Immunopathology and molecular diagnosis of autoimmune bullous diseases. J Cell Mol Med. 2007; 11:462-81.

11. Hans-Filho G, dos Santos V, Katayama JH, Aoki V, Rivitti EA, Sampaio SA, et al. An active focus of high prevalence of fogo selvagem on an Amerindian reservation in Brazil. Cooperative Group on Fogo Selvagem Research. J Invest Dermatol. 1996;107:68-75.

12. Rivitti EA, Sanches JA, Miyauchi LM, Sampaio SA, Aoki V, Diaz LA. Pemphigus foliaceus autoantibodies bind both epidermis and squamous mucosal epithelium, but tis sue injury is detected only in the epidermis. The Cooperative Group on Fogo Selvagem Research. J Am Acad Dermatol. 1994;31:954-8.

13. Warren SJ, Arteaga LA, Rivitti EA, Aoki V, Hans-Filho G, Qaqish BF, et al. The role of subclass switching in the pathogenesis of endemic pemphigus foliaceus. J Invest Dermatol. 2003;120:104-8.

14. Ding X, Aoki V, Mascaro JM Jr., Lopez-Swiderski A, Diaz LA, Fairley JA. Mucosal and mucocutaneous (generalized) pemphigus vulgaris show distinct autoantibody profiles. J Invest Dermatol. 1997; 109:592-6.

15. Bhol K, Natarajan K, Nagarwalla N, Mohimen A, Aoki V,
Ahmed AR. Correlation of peptide specificity and IgG subclass with pathogenic and nonpathogenic autoantibodies in pemphigus vulgaris: a model for autoimmunity. Proc Natl Acad Sci U S A. 1995;92:5239-43.

16. Jablonska S, Chorzelski TP, Beutner EH, Chorzelska J. Herpetiform pemphigus, a variable pattern of pemphigus. Int J Dermatol. 1975;14:353-9.

17. Anhalt GJ, Kim SC, Stanley JR, Korman NJ, Jabs DA, Kory M, et al. Paraneoplastic pemphigus. An autoimmune mucocutaneous disease associated with neoplasia. N Engl J Med. 1990;323:1729-35.

18. Hashimoto T. Immunopathology of paraneoplastic pemphigus. Clin Dermatol. 2001;19:675-82.

19. Hashimoto T, Kiyokawa C, Mori O, Miyasato M, Chidgey MA, Garrod DR, et al. Human desmocollin 1 (Dsc1) is an autoantigen for the subcorneal pustular dermatosis type of IgA pemphigus. J Invest Dermatol. 1997;109:127-31.

20. de Oliveira JP, Gabbi TV, Hashimoto T, Aoki V, Santi CG, Maruta CW, et al. Two Brazilian cases of IgA pemphigus. J Dermatol. 2003;30:886-91.

21. Velthuis PJ, Kater L, van der Tweel I, Meyling FG, Derksen RH, Hene RJ, et al. In vivo antinuclear antibody of the skin: diagnostic significance and association with selective antinuclear antibodies. Ann Rheum Dis. 1990;49:163-7.

22. Sousa JX Jr, Miyamoto D, Zimbres JM, Costa DV, Aoki V. Clinicopathological evaluation of in vivo epidermal nuclear fluorescence. Clin Exp Dermatol. 2009;34:314-8.

23. Giudice GJ, Emery DJ, Zelickson BD, Anhalt GJ, Liu Z, Diaz LA. Bullous pemphigoid and herpes gestationis autoantibodies recognize a common non-collagenous site on the BP180 ectodomain. J Immunol. 1993;151:5742-50.

24. Katz SI, Hertz KC, Yaoita H. Herpes gestationis. Immunopathology and characterization of the $\mathrm{HG}$ factor. J Clin Invest. 1976;57:1434-41.

25. Morrison LH, Labib RS, Zone JJ, Diaz LA, Anhalt GJ. Herpes gestationis autoantibodies recognize a $180-\mathrm{kD}$ human epidermal antigen. J Clin Invest. 1988;81:2023-6.

26. Chan LS, Ahmed AR, Anhalt GJ, Bernauer W, Cooper $\mathrm{KD}$, Elder MJ, et al. The first international consensus on mucous membrane pemphigoid: definition, diagnostic criteria, pathogenic factors, medical treatment, and prognostic indicators. Arch Dermatol. 2002;138:370-9.

27. Leverkus M, Schmidt E, Lazarova Z, Brocker EB, Yancey $\mathrm{KB}$, Zillikens D. Antiepiligrin cicatricial pemphigoid: an underdiagnosed entity within the spectrum of scarring autoimmune subepidermal bullous diseases? Arch Dermatol. 1999;135:1091-8.

28. Mutasim DF, Adams BB. Immunofluorescence in dermatology. J Am Acad Dermatol. 2001; 45:803-22; quiz 22-4.

29. Woodley DT, Burgeson RE, Lunstrum G, BrucknerTuderman L, Reese MJ, Briggaman RA. Epidermolysis bullosa acquisita antigen is the globular carboxyl terminus of type VII procollagen. J Clin Invest. 1988;81:683-7.

30. Wojnarowska F, Marsden RA, Bhogal B, Black MM. Chronic bullous disease of childhood, childhood 
cicatricial pemphigoid, and linear IgA disease of adults. A comparative study demonstrating clinical and immunopathologic overlap. J Am Acad Dermatol. 1988; 19:792-805.

31. Marinkovich MP, Taylor TB, Keene DR, Burgeson RE, Zone JJ. LAD-1, the linear IgA bullous dermatosis autoantigen, is a novel $120-\mathrm{kDa}$ anchoring filament protein synthesized by epidermal cells. J Invest Dermatol. 1996;106:734-8.

32. Beutner EH, Chorzelski TP, Reunala TL, Kumar V. Immunopathology of dermatitis herpetiformis. Clin Dermatol. 1991;9:295-311.

33. Zone JJ. Skin manifestations of celiac disease. Gastroenterology. 2005;128(4 Suppl 1):S87-91.

34. Van Hale HM, Gibson LE, Schroeter AL. HenochSchonlein vasculitis: direct immunofluorescence study of uninvolved skin. J Am Acad Dermatol. 1986;15(4 Pt 1):665-70.

35. de la Faille-Kuyper EH, de la Faille HB. An immunofluorescence study of lichen planus. $\mathrm{Br} \mathrm{J}$ Dermatol. 1974;90:365-71.

36. Kulthanan K, Jiamton S, Varothai S, Pinkaew S, Sutthipinittharm P. Direct immunofluorescence study in patients with lichen planus. Int $\mathrm{J}$ Dermatol. 2007; 46:1237-41.

37. Burnham TK, Neblett TR, Fine G.. Immunofluorescent "band" test for lupus erythematosus. II. Employing skin lesions. Arch Dermatol. 1970;102:42-50.

38. Gilliam JN, Cheatum DE, Hurd ER, Stastny P, Ziff M. Immunoglobulin in clinically uninvolved skin in systemic lupus erythematosus: association with renal disease. J Clin Invest. 1974;53:1434-40.

39. Aoki V, Rivitti EA, Ito LM, Hans-Filho G, Diaz L. Perfil historico da imunopatogenia do pênfigo foliaceo endemico (fogo selvagem)* Historical profile of the immunopathogenesis of endemic pemphigus foliaceus (fogo selvagem)*. An Bras Dermatol. 2005;80:287-92

40. Li N, Aoki V, Hans-Filho G, Rivitti EA, Diaz LA. The role of intramolecular epitope spreading in the pathogenesis of endemic pemphigus foliaceus (fogo selvagem). J Exp Med. 2003;197:1501-10.

41. Ishii K, Amagai M, Hall RP, Hashimoto T, Takayanagi A, Gamou S, et al. Characterization of autoantibodies in pemphigus using antigen-specific enzyme-linked immunosorbent assays with baculovirus-expressed recombinant desmogleins. J Immunol. 1997;159:2010-7.

42. Mimouni D, Foedinger D, Kouba DJ, Orlow SJ, Rappersberger K, Sciubba JJ, et al. Mucosal dominant pemphigus vulgaris with anti-desmoplakin autoantibodies. J Am Acad Dermatol. 2004;51:62-7.

43. Lessey E, Li N, Diaz L, Liu Z. Complement and cuta neous autoimmune blistering diseases. Immunol Res. 2008;41:223-32.

44. Gammon WR, Briggaman RA, Inman AO 3rd, Queen LL, Wheeler CE. Differentiating anti-lamina lucida and antisublamina densa anti-BMZ antibodies by indirect immunofluorescence on $1.0 \mathrm{M}$ sodium chlorideseparated skin. J Invest Dermatol. 1984;82:139-44.

\author{
MAILING ADDRESS / ENDEREÇO PARA CORRESPONDÊNCIA: \\ Valéria Aoki \\ Av. Dr. Enéas de Carvalbo Aguiar, 255 \\ Laboratório de Imunopatologia Cutânea \\ $3^{\circ}$ andar ICHC, sala 3.016 \\ 05403002 São Paulo - SP, Brazil \\ Pbone/fax: +551130698036 \\ E-mail:valaoki@botmail.com
}


This article has received corrections asked by theeditor on N ov/2010 in agreement with the ERRATUM published in Volume 85 Number 6. (http://www.scielo.br/pdf/abd/v85n6/v85n6a35.pdf) 